\title{
Regenerated Retinal Ganglion Cell Axons Can Form Well-Differentiated Synapses in the Superior Colliculus of Adult Hamsters
}

\author{
D. A. Carter, G. M. Bray, and A. J. Aguayo \\ Center for Research in Neuroscience, The Montreal General Hospital Research Institute and McGill University, Montreal, \\ Quebec, Canada H3G 1 A4
}

To investigate in adult animals the distribution and differentiation of the synapses made by axotomized CNS neurons whose regenerating axons are guided back to their natural targets in the brain, we attached an autologous peripheral nerve (PN) graft $2-3 \mathrm{~cm}$ in length to the ocular stump of a transected optic nerve (ON) in adult hamsters, inserted the distal end of the graft into the superior colliculus (SC), and, 6-8 weeks later, labeled the retinal ganglion cell (RGC) axons that entered the SC with HRP orthogradely transported from the eye. By light microscopy, regenerated RGC axons extended from the graft into the retinorecipient layers of the $\mathrm{SC}$ for up to $500 \mu \mathrm{m}$, distances that approximate the lengths of normal RGC arbors. We compared 698 control and 758 regenerated HRP-labeled axon terminals from 4 intact and 4 experimental animals by electron microscopy. The structure of the regenerated RGC terminals, the type of synaptic contacts formed, the ratios of contacts to terminal perimeter, and the domains of the postsynaptic neurons contacted were similar to those of controls. These results indicate that regenerated RGC axons can form well-differentiated synapses in the SC. Morphological differences between the regenerated and control synapses were the larger size of some regenerated terminals, the greater mean length of the regenerated synapses, and the higher proportion of contacts with dendrites that contained vesicles.

The synaptic differentiation attained by these reformed retinocollicular projections suggests that regenerating CNS axons and their target neurons in the adult mammalian brain may retain or reexpress certain molecular determinants of normal connectivity. The significance of these anatomical observations is underscored by the recent electrophysiological demonstration that such regenerated RGC axons can activate SC neurons transynaptically (Keirstead et al., 1989).

Injury to fiber tracts in the adult mammalian CNS may lead to the permanent disconnection of groups of neurons because the cut central axons fail to regrow the lengths needed to synapse

\footnotetext{
Received Mar. 9, 1989; revised May 31, 1989; accepted June 2, 1989.

The technical assistance of M. David, S. Shinn, J. Trecarten, and W. Wilcox is gratefully acknowledged. We thank J. Adam, Dr. S. Suissa, and Dr. J. Hanley for the statistical assistance and Dr. M. Rasminsky for reading the manuscript. Financial support was provided by the Medical Research Council, the Multiple Sclerosis Society of Canada, the Spinal Cord Research Foundation, the Daniel Heumann Fund for Spinal Cord Research, and the M. Wiesberg Vision Regeneration Fund.

Correspondence should be addressed to A. J. Aguayo at the above address.

Copyright (C) 1989 Society for Neuroscience 0270-6474/89/114042-09\$02.00/0
}

on their distant targets. Although it has now been established that several classes of axotomized CNS neurons are capable of a lengthy regrowth when their damaged axons interact with nonneuronal components of peripheral nerve (PN) grafts (Aguayo, 1985), the extent to which the regenerated central axons can penetrate the CNS and reform well-differentiated synapses has not been determined. Certain regenerative responses of the injured retinal ganglion cells (RGCs) of adult rodents provide an opportunity to investigate these issues experimentally. For example, when one optic nerve (ON) is transected intraorbitally in rats and the ocular stump is anastomosed to a PN graft that links the eye and the superior colliculus (SC), the axons of the injured RGCs reach the SC by extending along the graft for distances nearly twice as great as those of normal retinocollicular projections. While some of these regenerated RGC axons reenter the $\mathrm{SC}$ and form synapses, their precise terminal distribution in the SC and the morphological characteristics of their preand postsynaptic structures were not defined (Vidal-Sanz et al., 1987). The importance of proving in adult mammals that terminal synaptic differentiation can indeed follow the regrowth of axons into the CNS prompted the present qualitative and quantitative ultrastructural study in adult hamsters of terminals of RGC axons that extend into the SC across similar PN grafts. Our findings have previously been published in abstract form (Carter et al., 1988).

\section{Materials and Methods}

The right $O N$ was transected behind the sclera in 12 adult female hamsters (Mesocricetus auratus) 90-120 d old. A segment of autologous peroneal nerve $2-3 \mathrm{~cm}$ in length was excised from the leg and sutured to the ocular stump of the transected ON, and the remainder of the PN graft was extended extracranially beneath the scalp (Vidal-Sanz et al., 1987). Five to 7 weeks later, when RGC axons had grown along such grafts (Vidal-Sanz et al., 1987), the distal end of the graft was divided into small bundles that were inserted into the lateral part of the superficial SC, exposed on the ipsilateral side by resecting part of the overlying occipital lobe. After an additional 2-3 weeks, the left $O N$ was transected to cause more extensive denervation of the targeted SC. Four to 6 weeks later, $3 \mu \mathrm{l}$ of $30 \%$ HRP (Boeringher, Mannheim) were injected into the vitreous body of the right eye. After $2 \mathrm{~d}$, the animals were perfused with $2.5 \%$ glutaraldehyde and $0.5 \%$ paraformaldehyde in $0.1 \mathrm{M}$ phosphate buffer, and the eyes, PN grafts, and brains were dissected. For all procedures, the hamsters were anesthetized with intraperitoneal pentobarbital $(35 \mathrm{mg} / \mathrm{kg})$.

Serial transverse sections of the midbrain were cut at $50-70 \mu \mathrm{m}$ with a vibrating microtome and doubly reacted for HRP histochemistry (Lemann et al., 1985) for light and electron microscopic visualization of the terminal portions of the regenerated retinal axons. The sections were first processed at $\mathrm{pH} 4.0$ with tetramethylbenzidine as the chromagen. 
The HRP-tetramethylbenzidine reaction product was then stabilized by reacting the sections at $\mathrm{pH} 7.4$ with diaminobenzidine-cobalt (Lemann et al., 1985). The sections were stained with osmium tetroxide, flat-embedded in epoxy resin, and surveyed by light microscopy (LM). SC areas with HRP reaction product were drawn by camera lucida and, in the 4 animals showing the most extensive HRP labeling, serial ultrathin sections were prepared for electron microscopy (EM). Control retinocollicular axon terminals were similarly identified and studied after orthograde HRP labeling in 4 intact hamsters of comparable ages.

For the PN-grafted SCs, we photographed all HRP-labeled axon terminals in EM sections separated by 6-7 $\mu \mathrm{m}$. This interval was chosen to minimize the chances of multiple sampling of the same terminal because the maximum diameter of 97 of the initial 100 regenerated terminals studied was less than $6.5 \mu \mathrm{m}$. For the control data, we examined HRP-labeled terminals from both the contra- and ipsilateral SCs. On the contralateral side, we photographed the labeled terminals within columnar zones, $11 \mu \mathrm{m}$ wide, that extended perpendicularly from the pial surface into the SC for approximately $1 \mathrm{~mm}$. On the ipsilateral side, we photographed labeled terminals from the retinorecipient zones (Chalupa and Rhoades, 1979; Frost et al., 1979; Jen et al., 1984). For quantitative analysis, we grouped data for HRP-labeled terminals from areas of comparable size in the contra- and ipsilateral control SCs.

The ultrastructural features of the regenerated and control terminals were compared in electron micrographs printed at 35,000 $\times$. Synapses were identified according to standard criteria (Palay and Chan-Palay, 1975); for quantitative analyses, obliquely sectioned synapses were eliminated if the synaptic cleft could not be visualized. From the same electron micrographs, other characteristics of the HRP-labeled terminals were calculated with the aid of an IRAS I tablet digitizer: perimeters, areas, and synapse lengths. Ratios of the number of synapses and of the total synaptic length to the terminal perimeter were calculated for each terminal.

Regenerated and control terminals were compared statistically with the aid of the SAS Program (SAS Institute, Inc., Cary, NC). Terminal areas, contacis/lerminal perimeter, synapse lengths, and total synaptic length/terminal perimeter for the experimental and control groups were compared by analysis of variance, using a "nested" design (Winer, 1971) for unbalanced data by comparing the ratios of the type III mean square for the 2 groups to the mean square for animals within each group, with 1 and 6 degrees of freedom. Contacts per terminal were compared by analyzing the different incidences of terminals with $0,1,2$, or $>2$ contacts with $a x^{2}$ test. The proportions of regenerated and control terminals that synapsed with vesicle-containing postsynaptic processes were compared by Student's $t$ test using each animal as the unit of analysis.

The present study does not address the question of the densities of RGC terminals within the reinnervated areas of the SC. Although labeled terminals were less frequently observed by EM in the SCs of the experimental animals than in the controls, it was neither possible nor justified to quantitate these differences. Comparisons of relative densities based on single-section analysis would be unreliable because of the larger size and possibly different shapes of the regenerated terminals, as well as the discontinuous nature of the HRP reaction product produced by the Lemann et al. (1985) technique. Serial EM reconstructions, which could circumvent this difficulty, were beyond the scope of the present study. Furthermore, to be meaningful, densities of regenerated RGC terminals should be related to the population of axons that entered the SC. In the present experiments, however, it was not feasible to determine how many regenerated axons emerged from the graft, although the number was presumably only a small proportion of normal (Villegas-Perez et al., 1988).

\section{Results}

By LM examination of SCs of the 4 control hamsters, the fine, discontinuous reaction product that is characteristic of the combined tetramethylbenzidine-diaminobenzidine-cobalt method of HRP visualization (Vidal-Sanz et al., 1987) was observed in the retinorecipient areas of the $\mathrm{SC}$, principally the stratum griseum superficiale (SGS) and stratum opticum (SO), but also to a lesser extent in stratum zonale and stratum griseum intermediale (SGI) (Chalupa and Rhoades, 1979; Frost et al., 1979; Jen et al., 1984). In the 12 experimental hamsters, the laterally

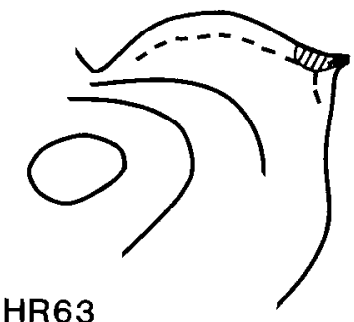

HR63

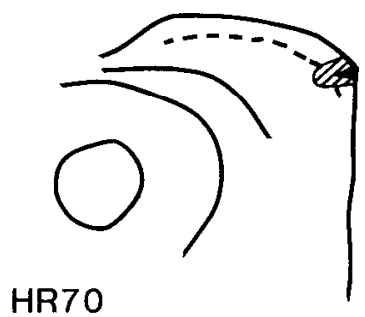

HR70

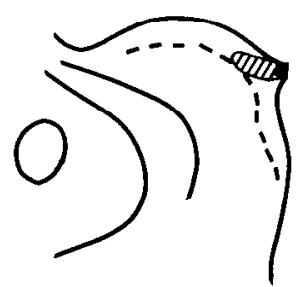

HR65

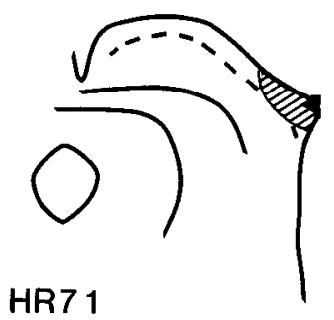

$1 \mathrm{~mm}$
Figure 1. Camera lucida drawings from transverse midbrain sections illustrating the region of the SC used for ultrastructural studies of regenerated RGC terminals. For each animal, an autologous peripheral nerve graft connected the ocular stump of one transected optic nerve with the ipsilateral SC. The solid areas represent the end of the PN graft; the cross-hatched areas delineate the extent of HRP labeling, as identified by LM. The broken line indicates the border between SGS (above) and SO (below). Axon terminals were observed within the cross-hatched areas and analyzed by EM. Scale bar, $1 \mathrm{~mm}$.

inserted PN grafts penetrated the superficial SC for distances up to $1 \mathrm{~mm}$ and ended within the SO or the lower SGS (e.g., solid areas in Fig. 1). In 9 of these animals, linearly arranged HRP reaction product was observed by $\mathrm{LM}$ in the terminal part of the graft and in the contiguous SO, but not in the subjacent SGI, in spite of axonal extensions lengthy enough to have reached the SGI in 6 of the 9 animals. In addition, these 9 animals showed particulate HRP labeling, which tended to be arranged in small clusters, throughout the dorsoventral extent of the SGS adjacent to the graft for distances that ranged from 175 to 500 $\mu \mathrm{m}$ from the end of the graft (e.g., cross-hatched areas in Fig. 1). Although the pattern of HRP labeling in the SGS suggested axonal arborizations, the discontinuous nature of the reaction product precluded their exact delineation.

For the present study, designed to investigate the ultrastructural characteristics of regenerated axon terminals, the 4 PNgrafted animals with the most abundant HRP reaction product in the SC were selected for EM (Fig. 1). In these animals, there were HRP-labeled axon terminals within the neuropile of the SC adjacent to the PN grafts (Table 1). Labeled RGC terminals were less frequently observed in ultrathin sections of the grafted SCs than in the controls. Most of the regenerated terminals had the ultrastructural characteristics of control retinocollicular terminals; dark background matrix, pale mitochondria, and dense accumulations of clear, spherical synaptic vesicles $40-70 \mathrm{~nm}$ in diameter (Huerta and Harting, 1984) (Figs. 2-4). The regenerated terminals in the superficial SC formed synaptic contacts on large or small dendritic profiles, some of which contained vesicles (Figs. 3, 4). As in the normal retinocollicular synapses, almost all of the regenerated contacts observed in single sections were asymmetric (Table 2). In addition to the terminal synapses, 1 axon segment in the control SCs showed an en passant synapse; in the grafted animals, 18 such axon segments were observed 


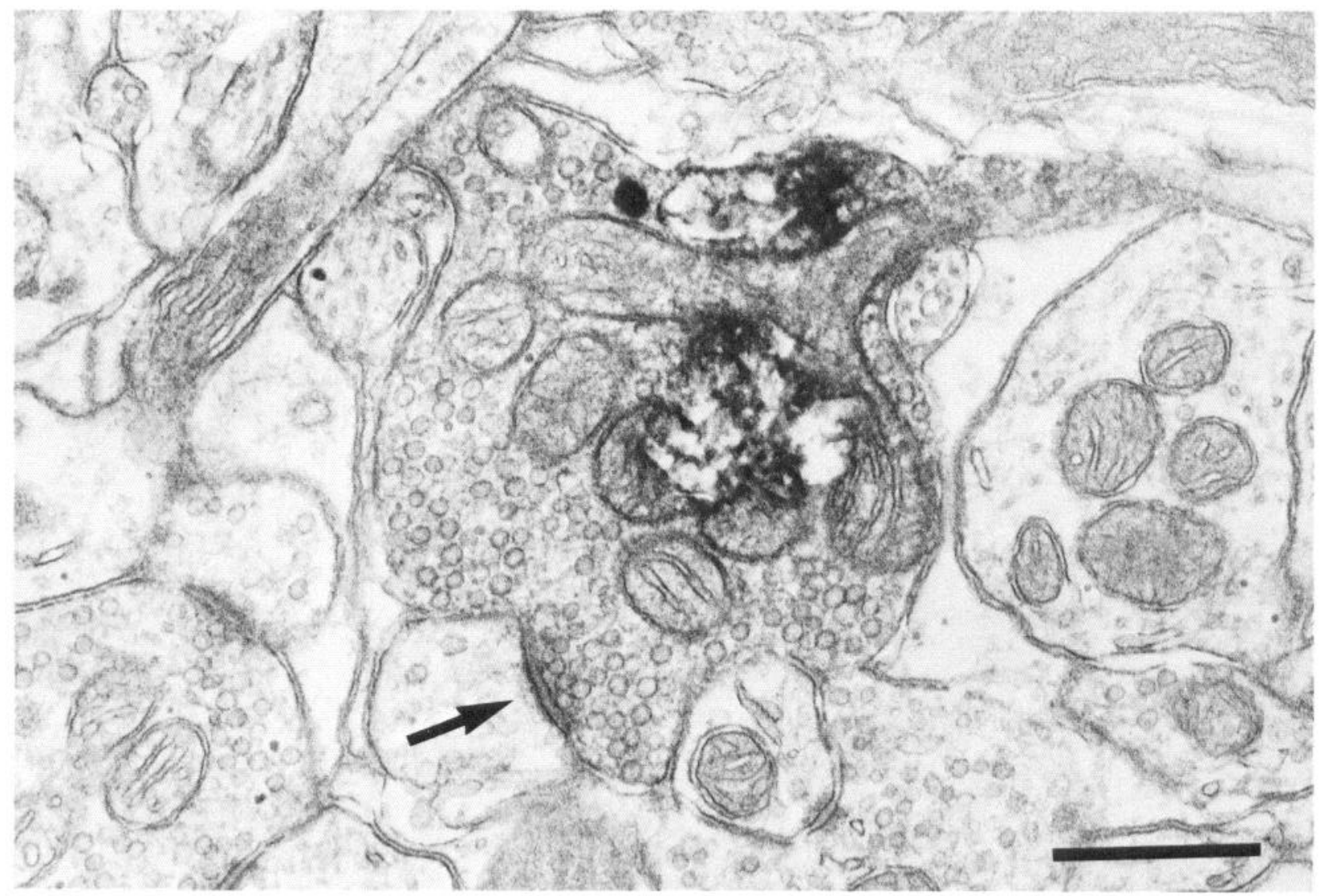

Figure 2. Electron micrograph of control retinocollicular axon terminal with 2 clumps of HRP reaction product, pale mitochondria, spherical vesicles, and an asymmetric synapse (arrow) onto a spine-like process. Scale bar, $0.5 \mu \mathrm{m}$.

(Fig. 4). Increased numbers of en passant contacts have also been reported during regeneration of retinotectal projections in goldfish (Hayes and Meyer, 1988b).

Ultrastructural features of the 758 regenerated terminals, identified in single EM sections separated by $6-7 \mu \mathrm{m}$, and of 698 control terminals were analyzed quantitatively (Fig. 5, Table 2).

Terminal size. The areas of $95.7 \%$ of the regenerated terminals fell within the control range (Fig. $5 \mathrm{~A}$ ), although the mean area of the regenerated terminals was statistically greater than that of the controls (Table 2). More precise comparisons of the sizes of the regenerated and control terminals would require serial EM reconstructions because measurements of terminal size in single sections do not take into account possible differences in shape or orientation. Because the purpose of this study was to examine a large sample of axon terminals, such 3-dimensional reconstructions were not attempted.

Synaptic junctions. More than $95 \%$ of both the regenerated and control synaptic junctions were judged to be asymmetric when examined in single sections (Table 2). Two-thirds of the regenerated terminals and approximately one-half of the control terminals showed at least one synaptic junction in single sections. Individual regenerated terminals also had more synaptic contacts than did the controls (Table 2). These differences may reflect the larger size of the regenerated terminals because the ratios of synapse number to terminal perimeter were not significantly different for the regenerated and control terminals (Fig. 5B, Table 2).
Length of synaptic contacts. Measured in single electron micrographs (Table 2), the mean length of the postsynaptic densities of the regenerated terminals was greater than that of the controls, although there was considerable overlap between the 2 groups (Fig. 5C). Statistically, the proportions of the terminal perimeters that showed synaptic specialization were significantly greater for the regenerated terminals than for the controls (Table 2, Fig. 5D).

Postsynaptic profiles. All the control synapses $(n=471)$ and all but one of the 901 regenerated synapses were axodendritic (Table 2); one regenerated terminal formed a synaptic contact with an SC nerve cell body. Similar proportions of regenerated and control synaptic junctions were distributed on profiles that could be identified as dendritic shafts or spines (Table 2, Fig. 6). Although the percentage of the postsynaptic profiles that contained vesicles was greater for the regenerated terminals than for the controls (Table 2), the frequency with which such postsynaptic stuctures synapsed with another dendrite (i.e., formed serial synapses) in the same section was similar for the regenerated and control animals (Table 2; Fig. 3, B, C).

\section{Discussion}

The aim of this anatomical study in adult hamsters was to investigate the early synaptic events made possible by the regeneration of axons from, and into, the injured adult mammalian CNS. Six to 8 weeks after the caudal tip of a PN graft was inserted into the $\mathrm{SC}$, some of the RGC axons that elongated through the PN grafts for distances of $2-3 \mathrm{~cm}$ had reentered the 

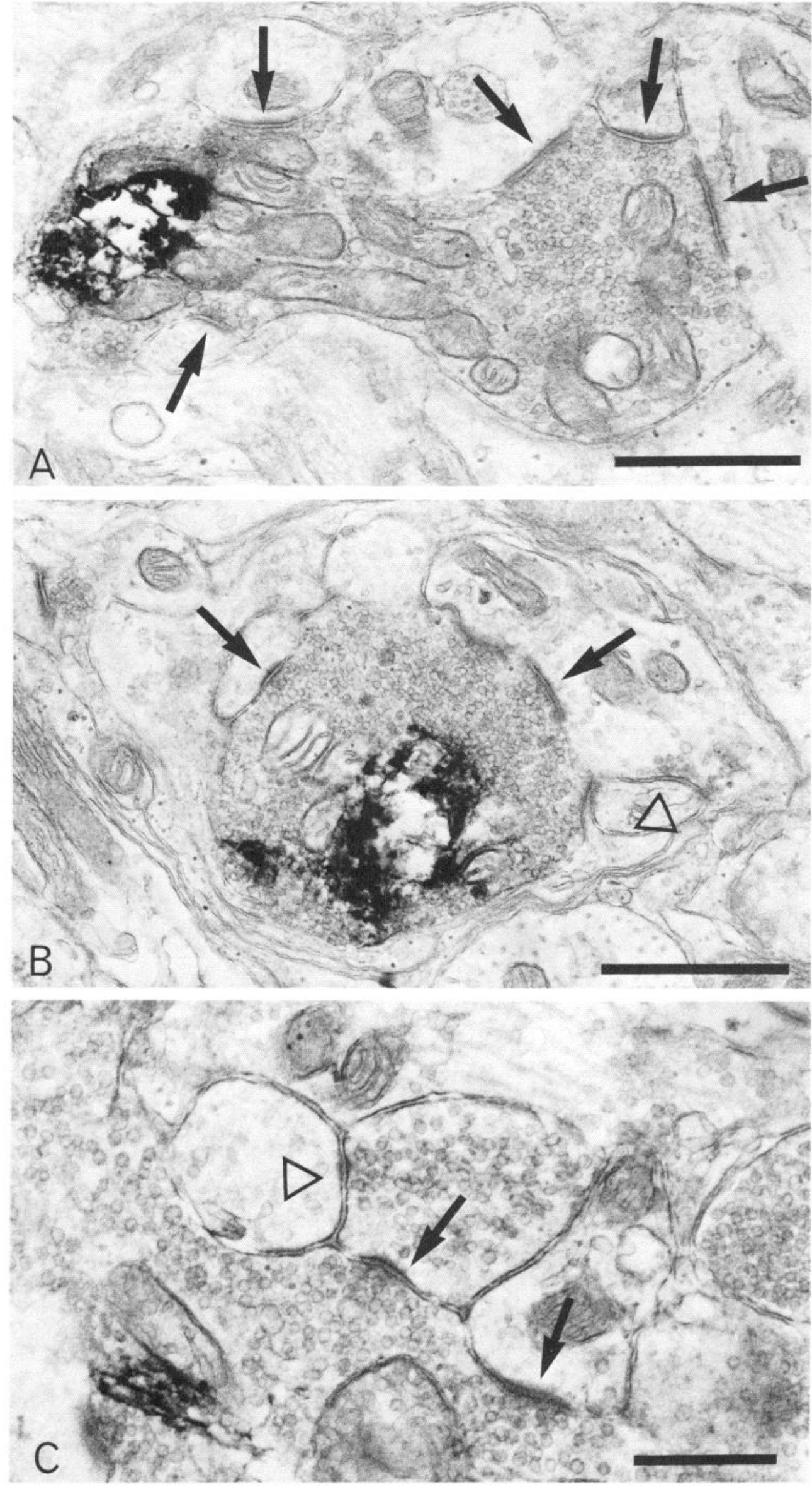

Figure 3. Regenerated retinocollicular axon terminals in the superficial SC contain HRP reaction product. $A$, This terminal contains several pale mitochondria and densely packed spheroidal synaptic vesicles. There are 5 asymmetric synaptic contacts (arrows) with dendritic shafts or spine-like processes. Scale bar, $1 \mu \mathrm{m}$. $B$, A regenerated RGC axon terminal shows asymmetric synaptic junctions (arrows) with a spinelike process (at left) and a larger dendritic profile (at right), which contains scattered vesicles and forms a serial synapse with another dendritic spine (open arrowhead). Scale bar, $1 \mu \mathrm{m}$. $C$, Higher magnification of part of an HRPlabeled (lower-left) axon terminal that forms asymmetric contacts with 2 spinelike processes (arrows), one of which contains pleomorphic synaptic vesicles and forms a serial synapse (open arrowhead). Scale bar, $0.5 \mu \mathrm{m}$. 


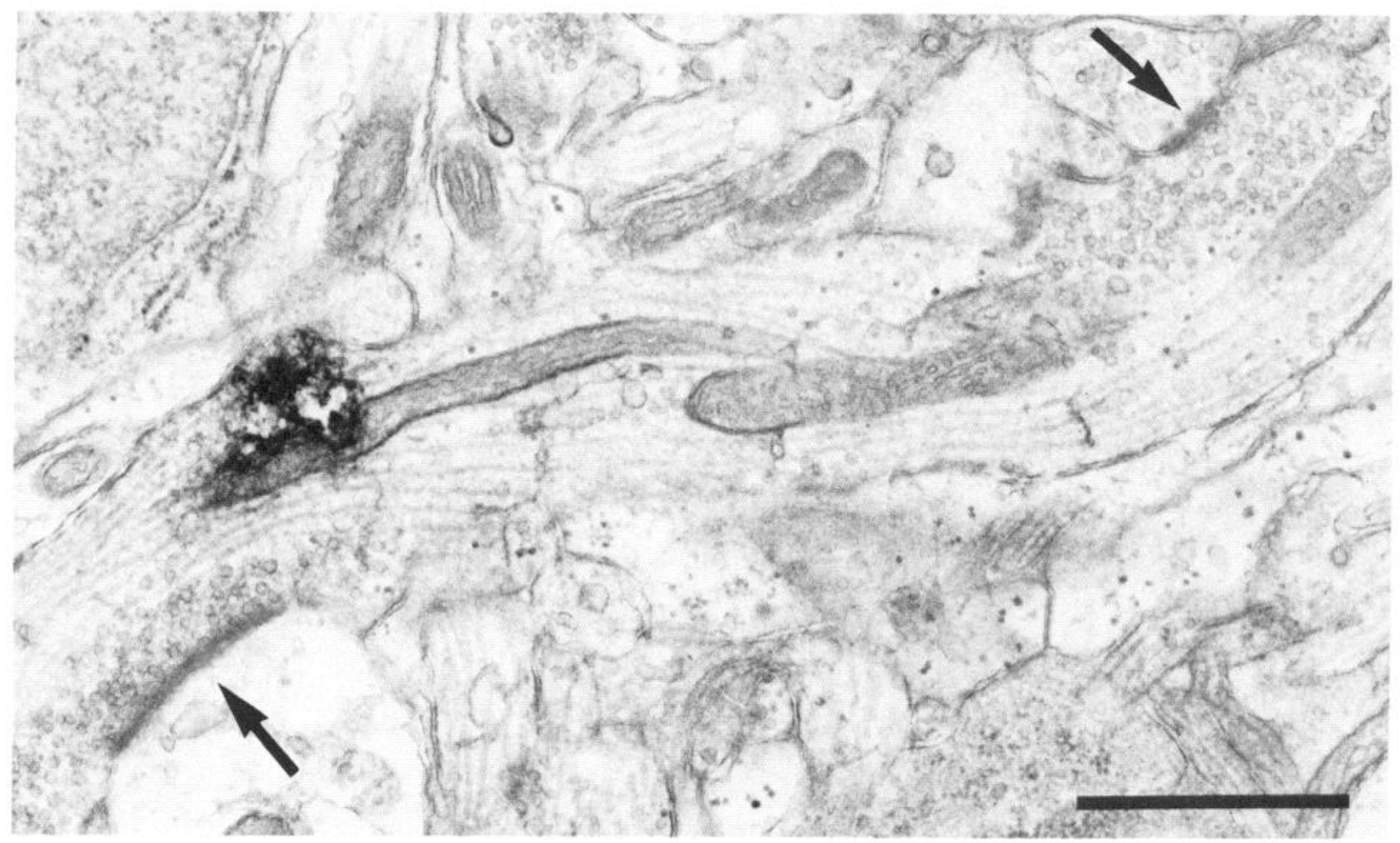

Figure 4. An HRP-labeled axon in the superficial SC of an experimental animal forms en passant synapses (arrows). Scale bar, $1 \mu \mathrm{m}$.

denervated SC. LM and EM studies of the HRP-labeled RGC axons that extended into the SC documented that (1) the regenerating $\mathrm{RGC}$ axons penetrated the $\mathrm{SC}$ for distances up to $500 \mu \mathrm{m}$ and terminated in the superficial layers of the SC that normally receive most retinal projections; (2) the ultrastructural features of the reformed RGC terminals and their synaptic junctions, virtually all of which were axodendritic, were strikingly similar to those of normal retinocollicular projections; (3) the morphometric differences between normal and regenerated axon terminals were similar to those reported in other studies where axonal growth leads to synaptogenesis in the vertebrate CNS.

\section{Penetration of regenerated $R G C$ axons in the $S C$}

The extension of the regenerating axons into the $\mathrm{SC}$ for distances up to $500 \mu \mathrm{m}$ from the tip of the graft approximates the lengths of the arborizations of the longest retinal afferents in the SC of normal hamsters (Sachs and Schneider, 1984). Since the PN grafts ended in or near the SO, the regenerating axons could have grown dorsally into the SGS or ventrally into the SGI. However, all the identified axon terminals were observed in the SO and SGS - the layers of the SC that normally receive most of the retinal inputs; regenerated axon terminals were not observed below the SO, areas of the SC that normally receive mostly nonretinal inputs (Huerta and Harting, 1984). Although this observation might suggest that the regenerating RGC axons specifically regrew to their most appropriate targets in the SC, the extensive denervation of the superficial SC may have had a nonspecific influence on the directed growth of these regenerating axons.

The present experiments, together with similar findings in the rat (Bray et al., 1988), provide evidence for the expression in the injured adult mammalian CNS of conditions that permit or facilitate the short-range extension of axons, as well as the formation of well-differentiated synapses in circumstances where the afferent fibers and the targeted neurons are both indigenous to the CNS. This pattern of axon extension and the formation of synapses within the superficial layers of the SC is reminiscent of the terminal differentiation of retinofugal axons in rodents during (1) the development of the visual system (Sachs et al., 1986), (2) the reinnervation that follows optic tract lesions in the immediate postnatal period (So et al., 1981), and (3) the transplantation of fetal retinas to the midbrain of immature hosts (McLoon and Lund, 1980; McLoon et al., 1982; Hankin and Lund, 1987). The mechanisms responsible for such reentry of growing axons into the CNS are unknown, but local changes caused by the denervation of the SC and/or influences arising from molecules released by the PN segments used as grafts may be involved (McLoon and Lund, 1980; Bjorklund and Stenevi, 1984; Cotman and Nieto-Sampedro, 1984; Heumann et al., 1987; Bixby et al., 1988).

\section{Reformation of axodendritic synapses in the SC}

In terms of their internal structure, type of synaptic specialization, and ratio of synaptic contacts to unit length of terminal perimeter, the ultrastructural features of the regenerated axon terminals had a remarkable likeness to the retinofugal connections in the SCs of intact hamsters. The extent to which mechanisms intrinsic to the regenerating neurons or to their targets (Palay and Chan-Palay, 1975; Campbell and Frost, 1987) influenced this morphological differentiation is a matter of speculation. This question is being explored in the adult mammalian CNS by examining the terminals formed by regenerating RGC 
A

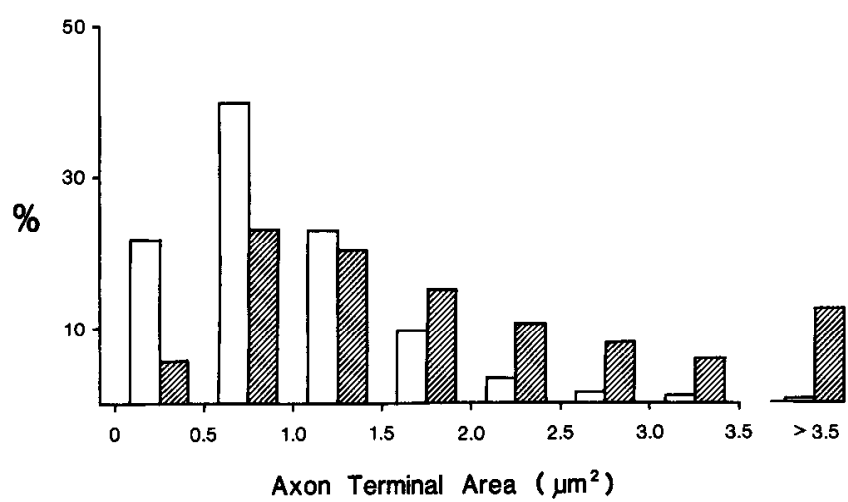

C

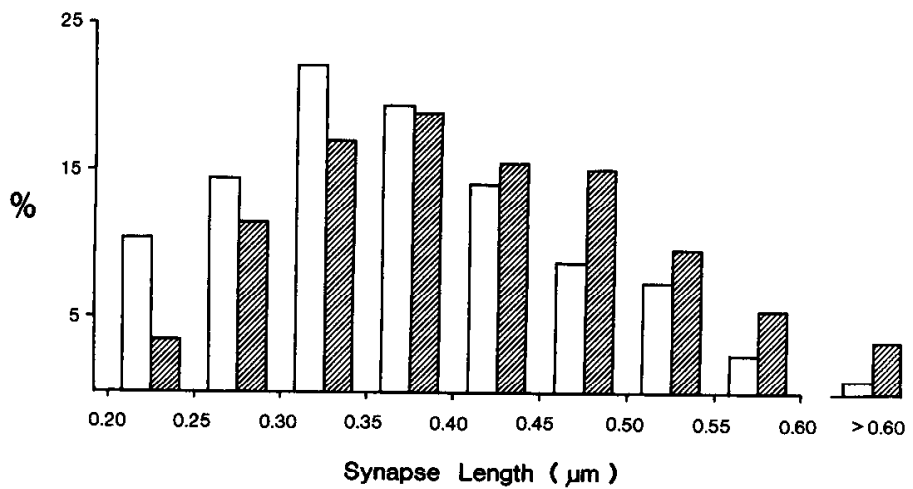

B

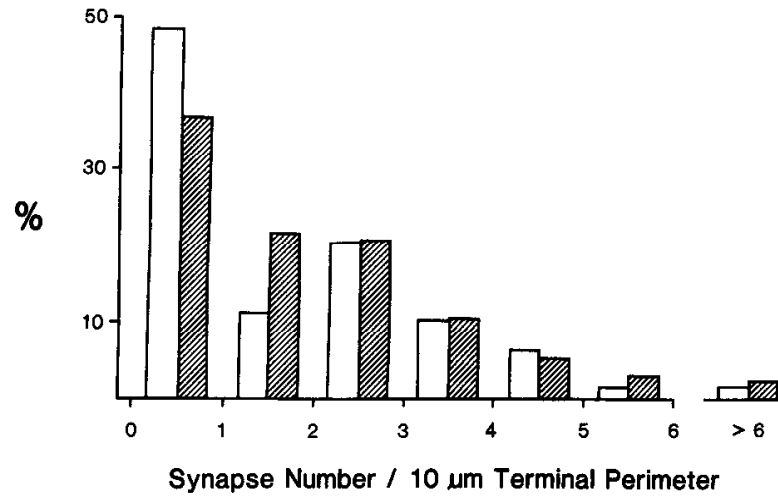

D

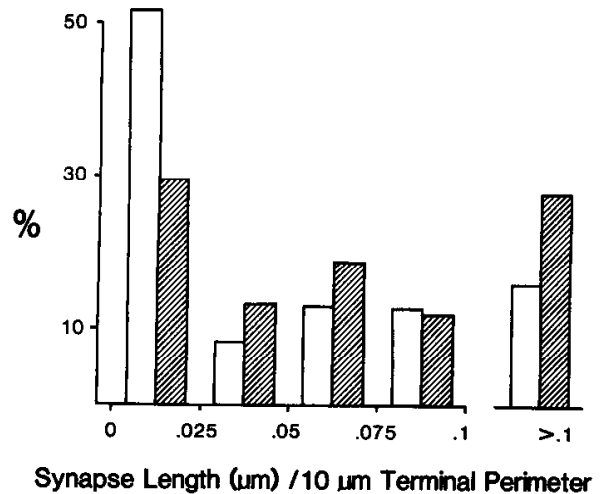

Figure 5. Histograms comparing regenerated (hatched bars) and control (open bars) RGC axon terminals in the SCs of adult hamsters. Data for individual terminals in 4 grafted and 4 control hamsters were determined in single cross-section electron micrographs printed at $35,000 \times$. $A$, Area/ frequency distributions of 758 regenerated and 698 control axon terminals identified by the presence of HRP reaction product orthogradely transported from the eye. $B$, Numbers of synapses per $10 \mu \mathrm{m}$ of axon terminal perimeter. $C$, Lengths of regenerated and control synaptic junctions. $D$, Ratios of total synaptic length $(\mu \mathrm{m})$ per $10 \mu \mathrm{m}$ of axon terminal perimeter.

axons that have been guided into inappropriate CNS regions (Zwimpfer et al., 1989).

In the present study of regenerated RGC axons in adult hamsters, as in those of normal retinocollicular projections (Huerta and Harting, 1984), virtually all the terminals synapsed on dendritic spines or shafts rather than cell bodies. Moreover, the distribution of synapses on shafts or spines was similar for regenerated and control terminals. This apparent appropriateness of the postsynaptic neuronal domains suggests that active recognition or induction mechanisms are involved, a process that may be influenced by the availability of potential postsynaptic sites following the interruption of all natural retinal projections to the SC.

In the SCs of intact rodents, the terminals of some RGC axons synapse onto vesicle-containing profiles that are considered to be presynaptic dendrites of a subpopulation of SC neurons (Lund, 1969; Valverde, 1973; Houser et al., 1983; Mize, 1988). In the present study, the proportion of retinocollicular terminals that contacted vesicle-containing dendrites was greater for the regenerated terminals than for the controls. Such a change may indicate that the regenerating terminals preferentially contacted this subpopulation of SC neurons (Valverde, 1973), although we do not know if the expression of such vesicles in the postsynaptic neurons was altered by the removal of retinal inputs

\begin{tabular}{lll}
\hline Table 1. Features of PN-grafted SCs used for ultrastructural studies \\
& $\begin{array}{l}\text { Maximal extension of } \\
\text { regenerated axons } \\
\text { into } S C \\
(\mu \mathrm{m})\end{array}$ & $\begin{array}{l}\text { Number of } \\
\text { terminals } \\
\text { examined }\end{array}$ \\
Animal & 350 & 20 \\
\hline HR63 & 375 & 250 \\
HR65 & 225 & 65 \\
HR70 & 500 & 423 \\
HR71 & & \\
\hline
\end{tabular}




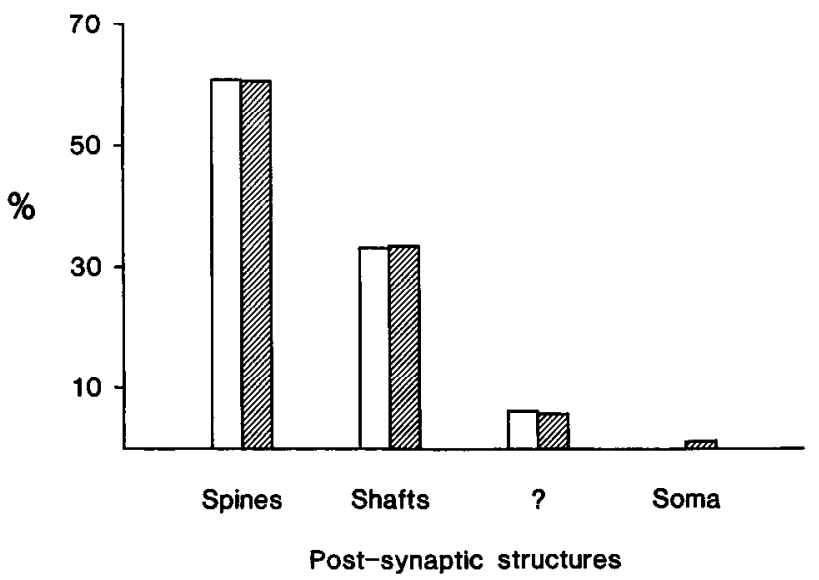

Figure 6. Postsynaptic domains of SC neurons contacted by RGC axon terminals labeled with orthogradely transported HRP. Regenerated (hatched bars) and control (open bars) RGC axon terminals showed similar distributions on spine-like profiles, dendritic shafts, neuronal perikarya (soma), or undefined (?) neural processes.

or their subsequent reinnervation. Another possibility is that the regenerated terminals may have arisen from a subpopulation of RGCs that preferentially contact vesicle-containing processes. In addition, we observed in single sections that some of these vesicle-containing dendrites were components of serial synapses. The similar proportions of regenerated and control RGC axon terminals that participated in such serial synapses (Table 2) suggest a tendency of the reformed RGC terminals to become incorporated into these complexes, which are a normal feature of the local circuitry of the SC (I und, 1969).

In the intact hamster, most retinal inputs to the SC come from the contralateral eye. These fibers terminate in retinorecipient layers of the superficial SC (mainly the SGS and the SO), while the smaller ipsilateral projection ends principally in the SO (Chalupa and Rhoades, 1979; Frost et al., 1979; Jen et al., 1984). In the present studies, in which regrowing RGC axons were all directed to the ipsilateral SC previously deprived of its retinal afferents, the formation of synapses by the regenerated RGC axon terminals was not concentrated in the SO but extended into the SGS, which is normally a target of the contralateral retinal inputs. Such a broadened deployment of ipsilateral RGC axons can also be induced experimentally in immature hamsters (Schneider, 1973; Mooney et al., 1985). In addition, the goldfish retinotectal projection, which normally projects contralatcrally, can innervate the main retinorecipient layers of the ipsilateral tectum that has been deprived of its normal retinal input (Meyer, 1978; Hayes and Meyer, 1988a). Furthermore, it has been reported that there is partial development of retinotopography by such abnormal projections in immature hamsters (Finlay et al., 1979) and in goldfish (Meyer, 1978). The extent, if any, of the retinotopic reorganization that is possible in adult hamsters remains to be determined.

\section{Morphological differences between the normal and regenerated synapses}

Compared with the controls, some of the regenerated terminals had larger areas, longer synaptic junctions, and more synaptic contacts with total lengths that covered greater proportions of the terminals. Such differences are consistent with findings in other vertebrates where renewed synaptogenesis is known to occur. In the goldfish optic tectum, for example, regenerating

\begin{tabular}{|c|c|c|}
\hline Variable & $\begin{array}{l}\text { Regenerated } \\
(n=4)\end{array}$ & $\begin{array}{l}\text { Control } \\
(n=4)\end{array}$ \\
\hline \multicolumn{3}{|l|}{ Terminals } \\
\hline Total number ${ }^{a}$ & 758 & $698^{b}$ \\
\hline Area $\left(\mu \mathrm{m}^{2}\right)^{a, c}$ & $1.96,0.06^{\circ}$ & $0.97,0.02$ \\
\hline Pale mitochondria (\%) & 94.6 & 95.7 \\
\hline \multicolumn{3}{|l|}{ Synaptic junctions } \\
\hline Total number & 901 & 471 \\
\hline Asymmetric (\%) & 98.8 & 97.4 \\
\hline \multicolumn{3}{|l|}{ Number/terminal $(\%)^{a}$} \\
\hline 0 & $34.5^{e}$ & 47.9 \\
\hline 1 & $37.4^{e}$ & 39.4 \\
\hline 2 & $16.7^{e}$ & 10.7 \\
\hline$>2$ & $11.4^{e}$ & 2.0 \\
\hline Mean number/terminal ${ }^{a}$ & 1.2 & 0.7 \\
\hline \multicolumn{3}{|l|}{ Number $/ 10 \mu \mathrm{m}$ terminal } \\
\hline Mean length $(\mu \mathrm{m})^{c, d}$ & $0.38,0.01^{e}$ & $0.31,0.01$ \\
\hline \multicolumn{2}{|c|}{ Length $(\mu \mathrm{m}) / 10 \mu \mathrm{m}$ terminal } & $0.36,0.01$ \\
\hline \multicolumn{3}{|l|}{ Postsynaptic structures } \\
\hline Total number & 901 & 471 \\
\hline With vesicles $(\%)^{c}$ & $48.0,2.7^{e}$ & $29.5,1.7$ \\
\hline \multicolumn{3}{|l|}{ Distribution (\%) } \\
\hline Somata & 0.1 & 0 \\
\hline \multicolumn{3}{|l|}{ Dendrites } \\
\hline Spine-like & 60.8 & 60.9 \\
\hline Shafts & 33.6 & 33.1 \\
\hline Undefined & 5.6 & 6.0 \\
\hline Serial synapses $(\%)$ & 1.0 & 1.2 \\
\hline
\end{tabular}

${ }^{a}$ Excluding axon segments with $e$ passant contacts.

${ }^{3} 666$ from contralateral SCs and 32 from ipsilateral SCs.

- Mean, standard error of the mean.

${ }^{d}$ Determined for 730 regenerated and 352 control synapses.

- Significantly different from control, $p<0.01$.

Not significantly different from control, $p>0.05$.

retinotectal terminals initially tend to be larger and to form longer synaptic contacts (Radel and Yoon, 1985). Although no comparable data are available for regencrated axon terminals in the mammalian CNS, larger terminals and longer, more frequent synapses per terminal have also been demonstrated in studies of the collateral sprouting by intact neurons in partially denervated fields (Raisman, 1969; Matthews et al., 1976; Chen and Hillman, 1987; Murray et al., 1987; Steward et al., 1988) and in situations where afferent fiber populations are decreased experimentally (Sotelo, 1975; Hillman and Chen, 1985). Because the reformed retinocollicular pathway of the present study likely originated from a small population of RGCs (VillegasPerez et al., 1988), some of the changes observed in the regenerated RGC axon terminals and their synapses in the SCs of these adult hamsters may also be a response to the diminished afferent/target ratio. In the goldfish, on the other hand, in which a full complement of RGC axons may eventually innervate the optic tectum (Murray et al., 1982), the ultrastructural features of the regenerated retinotectal terminals are reported to return to normal (Murray and Edwards, 1982; Radel and Yoon, 1985; 
Hayes and Meyer, 1988b). The possibility that the quantitative differences observed in adult hamsters may also change with longer periods of survival is being investigated in hamsters and other rodents with similar PN grafts (Bray et al., 1988). Because RGC axons that regenerate along PN grafts exhibit both spontaneous and light-induced electrical activity (Keirstead et al., 1985) and are capable of making functional contacts with SC neurons (Keirstead et al., 1989), it is possible that the persistence of this electrical activity may contribute to synaptic differentiation, an effect that has been documented for retinogeniculate connections during development (Kalil et al., 1986).

\section{Concluding remarks}

The present findings indicate that once the reapproximation of retinal growth cones and $\mathrm{SC}$ neurons is made possible by the elongation of RGC axons across $\mathrm{PN}$ grafts, the regenerated fibers can form well-differentiated synapses. Furthermore, the demonstration that such connectivity can occur in the adult mammalian CNS as the end result of extensive axonal regrowth raises the additional possibility that synaptic contacts may be restored spontaneously following injury to the mature CNS by the shortrange regrowth of axons interrupted near their targets or by the reestablishment of connections between nerve cells, such as interneurons, whose somata are close to each other.

The design and scope of the present experiments in adult hamsters did not permit a detailed study of other aspects of cellular recognition that are involved in the restoration of neuronal circuitry. These include the number and size of the arbors formed, the precise classes of SC neurons that are reinnervated, and whether or not there is a retinotopic order to the deployment of $\mathrm{RGC}$ axons that reach the SC. Nevertheless, the level of anatomical differentiation accomplished by the reformed synapscs appcars to be substantial enough to mediate the lightinduced transynaptic excitation or inhibition of tectal cells by regenerated RGC axons in similarly prepared experimental animals studied electrophysiologically (Keirstead et al., 1989).

\section{References}

Aguayo, A. J. (1985) Axonal regeneration from injured neurons in the adult mammalian central nervous system. In Synaptic Plasticity, C. W. Cotman, ed., pp. 457-484, Guilford, New York.

Bixby, J. L., J. Lilien, and L. F. Reichardt (1988) Identification of the major proteins that promote neuronal process outgrowth on Schwann cells in vitro. J. Cell Biol. 107: 353-361.

Bjorklund, A., and U. Stenevi (1984) Intracerebral neural implants: Neuronal replacement and reconstruction of damaged circuits. Annu. Rev. Neurosci. 7: 279-308.

Bray, G. M., M. Vidal-Sanz, and A. J. Aguayo (1988) Regenerated retinocollicular synapses cightecn months after substitution of the optic nerve by a peripheral nerve graft in adult rats. Soc. Neurosci. Abstr. 14: 654 .

Campbell, G., and D. O. Frost (1987) Target-controlled differentiation of axon terminals and synaptic organization. Proc. Natl. Acad. Sci. USA 84: 6929-6933.

Carter, D. A., G. M. Bray, and A. J. Aguayo (1988) Normal ultrastructural characteristics of regenerated retinocollicular synapses in adult hamsters. Neurosci. Lett. 32(Suppl.): 575.

Chalupa, L. M., and R. W. Rhoades (1979) An autoradiographic study of the retinotectal projection in the golden hamster. J. Comp. Neurol. 186: 561-570.

Chen, S., and D. E. Hillman (1987) Enlargement of synapses in the striatum following partial deafferentation. Soc. Neurosci. Abstr. 13: 1663.

Cotman, C. W., and M. Nieto-Sampedro (1984) Cell biology of synaptic plasticity. Science $225: 1287-1294$.

Finlay, B. L., K. G. Wilson, and G. E. Schneider (1979) Anomalous ipsilateral retinotectal projections in Syrian hamsters with early le- sions: Topography and functional capacity. J. Comp. Neurol. 183: 721-740.

Frost, D. O., K. F. So, and G. E. Schneider (1979) Postnatal development of retinal projections in Syrian hamsters: A study using autoradiographic and anterograde degeneration techniques. Neuroscience 4: 1649-1677.

Hankin, M. H., and R. D. Lund (1987) Role of the target in directing the outgrowth of retinal axons: Transplants reveal surface-related and surface-independent cues. J. Comp. Neurol. 263: 455-466.

Hayes, W. P., and R. L. Meyer (1988a) Retinotopically inappropriate synapses of subnormal density formed by surgically misdirected optic fibers in goldfish tectum. Dev. Brain Res. 38: 304-312.

Hayes, W. P., and R. L. Meyer (1988b) Normal and regenerating optic fibers in goldfish tectum: HRP-EM evidence for rapid synaptogenesis and optic fiber-fiber affinity. J. Comp. Ncurol. 274: 516-538.

Heumann, R., D. Lindholm, C. Bandtlow, M. Meyer, M. J. Radeke, T. P. Misko, E. Shooter, and H. Thoenen (1987) Differential regulation of mRNA encoding nerve growth factor and its receptor in rat sciatic nerve during development, degeneration, and regeneration: Role of macrophages. Proc. Natl. Acad. Sci. USA 84: 8735-8739.

Hillman, D. E., and S. Chen (1985) Plasticity in the size of presynaptic and postsynaptic membrane specializations. In Synaptic Plasticity, C. W. Cotman, ed., pp. 39-76, Guilford, New York.

Houser, C. R., M. Lee, and J. E. Vaughn (1983) Immunocytochemical localization of glutamic acid decarboxylase in normal and deafferented superior colliculus: Evidence for reorganization of gamma-aminobutyric acid synapses. J. Neurosci. 3: 2030-2042.

Huerta, M. F., and J. K. Harting (1984) The mammalian superior colliculus: Studics of its morphology and connections. In Comparative Neurology of the Optic Tectum, H. Vanegas, ed., pp. 687-773, Plenum, New York.

Jen, L. S., K. F. So, and H. H. Woo (1984) An anterograde HRP study of the retinocollicular pathways in normal hamsters and hamsters with one eye enucleated at birth. Brain Res. 294: 169-173.

Kalil, R. E., M. W. Dubin, G. Scott, and L. A. Stark (1986) Elimination of action potentials blocks the structural development of retinogeniculate synapses. Nature 323: 156-158.

Keirstead, S. A., M. Vidal-Sanz, M. Rasminsky, A. J. Aguayo, M. Levesque, and K. F. So (1985) Responses to light of retinal neurons regenerating axons into peripheral nerve grafts in the rat. Brain Res. 359: 402-406.

Keirstead, S. A., M. Rasminsky, Y. Fukada, D. A. Carter, A. J. Aguayo, and M. Vidal-Sanz (1989) Electrophysiologic responses in hamster superior colliculus evoked by regenerating retinal axons. Science (in press).

Lemann, W., C. B. Saper, D. B. Rye, and B. H. Wainer (1985) Stabilization of TMB reaction product for electron microscopic retrograde and anterograde fiber tracing. Brain Res. Bull. 14: 277-281.

Lund, R. D. (1969) Synaptic patterns of the superficial layers of the superior colliculus of the rat. J. Comp. Neurol. 135: 179-207.

Matthews, D. A., C. Cotman, and G. Lynch (1976) An electron microscopic study of lesion-induced synaptogenesis in the dentate gyrus of the adult rat. II. Reappearance of morphologically normal synaptic contacts. Brain Res. 115: 23-41.

McLoon, L. K., R. D. Lund, and S. C. McLoon (1982) Transplantation of reaggregates of embryonic neural retinae to neonatal rat brain: Diffcrentiation and formation of conncctions. J. Comp. Neurol. 205: 179-189.

McLoon, S. C., and R. D. Lund (1980) Specific projections of retina transplanted to rat brain. Exp. Brain Res. 40: 273-282.

Meyer, R. L. (1978) Deflection of selected optic fibers into a denervated tectum in goldfish. Brain Res. 155: 213-227.

Mize, R. R. (1988) Immunocytochemical localization of gamma-aminobutyric acid (GABA) in the cat superior colliculus. J. Comp. Neurol. 276: 169-187.

Mooney, R. D., B. G. Klein, A. M. Szczepanik, and R. W. Rhoades (1985) Extensive recrossing of retinotectal axons after neonatal unilateral superior collicular lesions in hamster. Dev. Brain Res. 19:297313.

Murray, M., and M. A. Edwards (1982) A quantitative study of the reinnervation of the goldfish optic tectum following optic nerve crush. J. Comp. Neurol. 209: 363-373.

Murray, M., S. Sharma, and M. A. Edwards (1982) Target regulation of synaptic number in the compressed retinotectal projection of goldfish. J. Comp. Neurol. 209: 374-385. 
Murray, M., L. F. Wu, and M. E. Goldberger (1987) Spared root deafferentation of cat spinal cord: Anatomical recovery. In Effects of Injury on Trigeminal and Spinal Somatosensory Systems, L. M. Pubols and B. J. Sessle, eds., pp. 261-271, Liss, New York.

Palay, S. L., and V. Chan-Palay (1975) A guide to the synaptic analysis of the neuropil. Cold Spring Harbor Symp. Quant. Biol. 40:1-16.

Radel, J. D., and M. G. Yoon (1985) Time-course of ultrastructural changes in regenerated optic fiber terminals of goldfish. Brain Res. 342: 168-171.

Raisman, G. (1969) Neuronal plasticity in the septal nuclei of the adult rat. Brain Res. 14: 25-48.

Sachs, G. M., and G. E. Schneider (1984) The morphology of optic tract axons arborizing in the superior colliculus of the hamster. J. Comp. Neurol. 230: 155-167.

Sachs, G. M., M. Jacobson, and V. S. Caviness, Jr. (1986) Postnatal changes in arborization patterns of murine retinocollicular axons. J. Comp. Neurol. 246: 395-408.

Schneider, G. E. (1973) Early lesions of superior colliculus: Factors affecting the formation of abnormal retinal projections. Brain Behav. Evol. 8: 73-109.

So, K. F., G. E. Schneider, and S. Ayres (1981) Lesions of the brachium of the superior colliculus in neonate hamsters: Correlation of anatomy with behaviour. Exp. Neurol. 72: 379-400.

Sotelo, C. (1975) Synaptic remodeling in mutants and experimental animals. In Aspects of Neural Plasticity, F. Vital-Durand and M. Jeannerod, eds., pp. 167-190, INSERM, Paris.
Steward, O., S. L. Vinsant, and L. Davis (1988) The process of reinnervation in the dentate gyrus of adult rats: An ultrastructural study of changes in presynaptic terminals as a result of sprouting. J. Comp. Neurol. 267: 203-210.

Valverde, F. (1973) The neuropil in superficial layers of the superior colliculus of the mouse: A correlated Golgi and electron microscopic study. Z. Anat. Entwickl.-Gesch. 142: 117-147.

Vidal-Sanz, M., G. M. Bray, M. P. Villegas-Perez, S. Thanos, and A. J. Aguayo (1987) Axonal regeneration and synapse formation in the superior colliculus by retinal ganglion cclls in the adult rat. J. Neurosci. 7: 2894-2909.

Villegas-Perez, M. P., M. Vidal-Sanz, G. M. Bray, and A. J. Aguayo (1988) Influences of peripheral nerve grafts on the survival and regrowth of axotomized retinal ganglion cells in adult rats. J. Neurosci. 8: $265-280$.

Winer, B. J. (1971) Statistical Principles in Experimental Design, pp. 359-366, McGraw-Hill, New York.

Zwimpfer, T. J., A. J. Aguayo, G. M. Bray, and D. G. Lawrence (1989) Synapse formation by regenerating retinal ganglion cell axons directed into an inappropriate target (the cerebellar cortex) in adult hamsters. Soc. Neurosci. Abstr. 15: 458. 